\title{
Inducible Costimulator (ICOS) and ICOS Ligand Signaling Has Pivotal Roles in Skin Wound Healing via Cytokine Production
}

\author{
Shintaro Maeda, Manabu Fujimoto, \\ Takashi Matsushita, Yasuhito Hamaguchi, \\ Kazuhiko Takehara, and Minoru Hasegawa \\ From the Department of Dermatology, Kanazawa University \\ Graduate School of Medical Science, Kanazawa, Japan
}

Skin wound healing is mediated by inflammatory cell infiltration of the wound site. Inducible costimulator (ICOS), expressed on activated T cells, and its ligand, ICOS ligand (ICOSL), expressed on antigen-presenting cells, have been considered a single receptor-ligand pair. Although the ICOS-ICOSL pathway participates in adaptive immunity, its roles in skin wound healing, which is mediated by innate immune responses, remain unknown. To clarify these roles, repair of excisional wounds was examined in $\mathrm{ICOS}^{-/-}$mice, ICOSL ${ }^{-1-}$ mice, and $\mathrm{ICOS}^{-/-} \mathrm{ICOSL} \mathrm{L}^{-/-}$ mice. Each mutant strain showed similar, dramatic delays in wound healing, especially at early times. Knockout mice showed suppressed keratinocyte migration, angiogenesis, and granulation tissue formation, and diminished T-cell, macrophage, and neutrophil infiltration. The loss of ICOS and/or ICOSL resulted in marked suppression of cytokine expression in wounds, especially the Th 2 cytokines interleukin (II)-4, II-6, and IL-10. T-cell transfer experiments and T-cell depletion therapy further clarified the important roles of ICOS expressed on T cells and its interaction with ICOSL. Application of II- 6 , but not II- 4 , to the wounds significantly increased the onset of early wound healing in mutant mice. Thus, our results indicate that ICOS-ICOSL costimulatory signaling has critical roles during wound healing, most likely by inducing IL-6 production. (Am J Pathol 2011, 179:2360-2369; DOI: 10.1016/j.ajpath.2011.07.048)

Skin wound healing starts immediately after an injury and consists of three general stages: i) an inflammatory stage that consists of platelet aggregation and recruitment of inflammatory cells to the wound site; ii) a proliferative phase that involves the migration and proliferation of keratinocytes, fibroblasts, and endothelial cells, leading to re-epithelialization and granulation tissue formation; and iii) a long remodeling phase. ${ }^{1,2}$ Migration of inflammatory cells to the wound site is important during wound repair. ${ }^{1-4}$ Numerous studies have demonstrated that many cytokines, chemokines, and growth factors produced by infiltrating cells or resident cells contribute extensively to the wound healing process. These factors stimulate the synthesis of extracellular matrix by local fibroblasts, generate new blood vessels, promote granulation tissue formation, and enhance the re-epithelialization that takes place by the migration of keratinocytes from the edges of the wound toward the center. ${ }^{1,2}$

Inducible costimulator (ICOS) is the third member of the CD28 family of costimulatory molecules, and is induced on the cell surface following T-cell activation. ${ }^{5-7}$ ICOSL (also called B7-H2, B7RP-1, LICOS, and GL50), the ligand of ICOS, is weakly expressed on antigenpresenting cells in the steady state and is up-regulated after activation of these cells. ${ }^{6-8}$ The ICOS-ICOSL pathway promotes T-cell activation, differentiation, and effector responses, and T cell-dependent B-cell responses. ICOS-mediated costimulation of $T$ cells leads predominantly to the production of effector cytokines such as IL-4 and IL-10 and, to a lesser extent, IL-2, interferon (IFN)- $\gamma$, and tumor necrosis factor (TNF) $-\alpha,{ }^{9}$ thereby playing a more important role in Th2 responses than Th1 responses. ${ }^{5,10-12}$ However, recent studies demonstrated that ICOS influences the expansion of follicular helper T cells, Th17 cells, and regulatory $T$ cells, indicating the complex roles of ICOS in several disease models. ${ }^{13-15}$ Because $\mathrm{ICOS}^{-1-}$ mice and $\mathrm{ICOSL}^{-1-}$ mice display similar defects in humoral immunity, ICOS and ICOSL have been considered a single receptor-ligand pair. ${ }^{16-18}$

It is generally accepted that ICOS-ICOSL signaling is critical for adaptive immunity, including autoimmunity,

Supported by grants-in-aid from the Ministry of Education, Culture, Sports, Science, and Technology of Japan.

Accepted for publication July 18, 2011.

Address reprint requests to Minoru Hasegawa, M.D., Ph.D., Department of Dermatology, Kanazawa University, Graduate School of Medical Science, 13-1 Takaramachi, Kanazawa, Ishikawa 920-8641, Japan. E-mail:minoruha@derma.m.kanazawa-u.ac.jp. 
allergy, infectious diseases, and transplantation. ${ }^{18-21}$ However, ICOSL is constitutively expressed, not only on B cells, but also on macrophages and dendritic cells that contribute to innate immunity. ${ }^{6,8}$ Therefore, it is possible that ICOS-ICOSL signaling may be contributing to innate immunity as well as adaptive immunity. In fact, recent studies suggest involvement of ICOS and ICOSL in innate immune disease models. ${ }^{22,23}$ As skin wound healing involves a strong innate immune component, we applied this model to mice deficient for ICOS and ICOSL to investigate the roles of these molecules in modulating innate immunity.

\section{Materials and Methods}

\section{Mice}

$\mathrm{ICOS}^{-/-}$mice and $/ \mathrm{COSL}^{-1-}$ mice were purchased from Jackson Laboratory (Bar Harbor, ME). $/ \mathrm{COS}^{-/-}$mice and ICOSL $^{-1-}$ mice were backcrossed 10 and 8 generations onto the C57BL/6 genetic background, respectively. Mating these $\mathrm{ICOS}^{-1-}$ mice with $I C O \mathrm{CSL}^{-1-}$ mice generated $\mathrm{ICOS}^{+/-} \mathrm{ICOSL}^{+/-}$mice, which were crossed to generate $I_{C O S}{ }^{-1-} I_{C O S L}^{-1-}$. To verify the ICOS or ICOSL genotype, PCR amplification of each gene was conducted using genomic DNA from each mouse. All mice were housed in a specific pathogen-free barrier facility and screened regularly for pathogens. Eight- to 10-weekold male mice were used. The Committee on Animal Experimentation of Kanazawa University Graduate School of Medical Science approved all studies and procedures, including the use of diethyl ether for anesthesia.

\section{Wounding and Macroscopic Examination}

Mice were anesthetized and their backs shaved and cleaned with $70 \%$ alcohol. Four full-thickness excisional wounds per mouse were made using a disposable, sterile 6-mm biopsy punch (Kai, Tokyo, Japan), as described elsewhere. ${ }^{24}$ After surgery, mice were caged individually. Photos of the wounds were taken each day, and the open wound area was calculated and compared to that of the previous day using the free-hand tool of Photoshop Elements (Adobe Systems, Tokyo, Japan). No signs suggestive of local infection were detected in the wounded skin.

\section{Histological Examination and Immunohistochemistry}

After the mice were euthanized, wounds were harvested with a 2-mm rim of unwounded skin tissue. The wounds were cut into halves laterally, fixed in 3.5\% paraformaldehyde, and were then paraffin embedded. Six-micrometer sections were stained with hematoxylin and eosin (H\&E), or were immunostained. For immunohistochemistry, deparafinized sections were treated with endogenous peroxidase blocking reagent (DAKO Cytomation A/S, Copenhagen, Denmark) and proteinase K (DAKO Cytomation A/S) for 6 minutes at room temperature. Sections were then incubated with rat monoclonal antibodies spe- cific for myeloperoxidase (Neomarkers, Fremont, CA), macrophages (clone F4/80; Abcam, Cambridge, UK), CD3 (Serotec, Kidlington, UK), CD31 (BD Pharmingen, Franklin Lakes, $\mathrm{NJ})$, and $\alpha$-smooth muscle actin ( $\alpha$-SMA; Sigma-Aldrich, St. Louis, MO). Rat IgG (Southern Biotechnology Associates Inc., Birmingham, AL) was used as a control for nonspecific staining. Sections were then incubated sequentially $\left(20\right.$ minutes, $37^{\circ} \mathrm{C}$ ) with a biotinylated rabbit anti-rat IgG secondary antibody (Ab) (Vectastain ABC method, Vector Laboratories, Burlingame, $\mathrm{CA}$ ), then horseradish peroxidase-conjugated avidin-biotin complexes. Sections were washed three times with PBS between incubations. Sections were developed with 3,3'-diaminobenzidine tetrahydrochloride and hydrogen peroxide, and then counterstained with methyl green. Numbers of myeloperoxidase-positive neutrophils, F4/80positive macrophages, and CD3-positive T cells were determined by counting in nine high-power fields (0.07 $\mathrm{mm}^{2}$, magnification, $\times 400$ ) in the wound bed per section. Among the nine fields, six fields were selected from both edges of the wound bed, and the remaining three fields were chosen from the middle of the wound bed. The epithelial gap, which represents the distance between the leading edge of migrating keratinocytes, was measured in H\&E-stained sections of wounds. We identified the area that consisted of newly formed capillaries and the collection of fibroblasts and macrophages as granulation tissue. Wound sections were visualized by microscopy (BX50; Olympus, Tokyo, Japan) with images collected using a digital camera (DP70; Olympus). After this, the area of granulation tissue was gated and measured using the same system. Vessel density, defined as CD31positive regions, was measured in the whole wound bed areas using Photoshop Elements and was expressed as a percentage of this whole.

\section{T-Cell Depletion}

For T-cell depletion studies, $100 \mu \mathrm{g}$ of anti-mouse Thy 1.2, monoclonal Ab (mAb) (BD Pharmingen) was injected intravenously 24 hours before wounding, as described previously. ${ }^{25}$

\section{T-Cell Transfer}

Single-cell splenic leukocyte suspensions were generated by gentle homogenization. Immunomicrobeads (Miltenyi Biotec, Bergisch Gladbach, Germany) were used to purify T-cell populations according to the manufacturer's instructions. $2.0 \times 10^{6} \mathrm{CD}^{+}{ }^{+} \mathrm{T}$ cells, $\mathrm{CD} 4^{+} \mathrm{T}$ cells, or $\mathrm{CD}^{+} \mathrm{T}$ cells/mouse were transferred intravenously to indicated recipient mice.

\section{Real-Time Reverse-Transcription Polymerase Chain Reaction}

Total RNAs were extracted from injured skin samples using Qiagen RNeasy spin columns (Qiagen, Crawley, UK) and digested with DNase I (Qiagen) to remove chromosomal DNA in accordance with the manufacturer's 
protocols. Total RNA was reverse-transcribed to cDNA using Reverse Transcription System with random hexamers (Promega, Madison, WI). Real-time quantitative RTPCR was performed using the TaqMan system (Applied Biosystems, Foster City, CA) on an ABI Prism 7000 Sequence Detector (Applied Biosystems) according to the manufacturer's instructions. TaqMan probes and primers for IL-4, IL-6, IL-10, TNF- $\alpha$, connective tissue growth factor (CTGF), platelet-derived growth factor (PDGF), transforming growth factor (TGF)- $\beta$, vascular endothelial growth factor (VEGF), and glyceraldehyde-3-phosphate dehydrogenase (GAPDH) were purchased from Applied Biosystems. Relative expression of real-time PCR products was determined using the $\Delta \Delta \mathrm{C}_{\mathrm{T}}$ technique. Briefly, each set of samples was normalized using the difference in threshold cycle $\left(\mathrm{C}_{\mathrm{T}}\right)$ between the target gene and housekeeping gene (GAPDH): $\Delta \mathrm{C}_{\mathrm{T}}=\left(\mathrm{C}_{\mathrm{T} \text { target gene }}{ }^{-}\right.$ $\mathrm{C}_{\mathrm{T} \text { GAPDH }}$ ). Relative mRNA levels were calculated by the expression $2^{-\Delta \Delta C \mathrm{~T}}$, where $\Delta \Delta \mathrm{C}_{\mathrm{T}}=\Delta \mathrm{C}_{\mathrm{T} \text { sample }}-\Delta \mathrm{C}_{\mathrm{T} \text { calibrator. }}$ Each reaction was performed a minimum of three times.

\section{Cytokine Concentration in Tissues}

Samples of whole wounds were homogenized in $600 \mu \mathrm{L}$ of lysis buffer [10 mmol/L PBS, $0.1 \%$ sodium dodecyl sulfate, $1 \%$ Nonidet P- $40,5 \mathrm{mmol} / \mathrm{L}$ ethylenediaminetetraacetic acid (EDTA)] containing a complete protease inhibitor mixture (Roche Diagnostics $\mathrm{GmbH}$, Mannheim, Germany) to extract proteins. Homogenates were centrifuged at $22,000 \times g$ for 15 minutes at $4^{\circ} \mathrm{C}$ to remove debris. $^{24}$

The concentrations of IL-6, IL-10, IFN- $\gamma$, TNF- $\alpha$, and monocyte chemotactic protein (MCP)-1 in supernatants were determined using the BD Cytometric Bead Array mouse inflammation kit (BD Biosciences, San Jose, CA) according to the manufacturer's protocol. Flow cytometric analysis was performed using a FACSCalibur flow cytometer (BD Biosciences). Total protein in the supernatant was measured with the Bicinchoninic Acid Protein Assay kit (Thermo Fischer Scientific Inc., Waltham, MA).

\section{Application of Cytokines}

An optimal concentration of cytokines was applied to each wound in $20 \mu \mathrm{L}$ of phosphate-buffered saline. Cytokines were applied to wounds immediately after wounding and every 24 hours thereafter. Recombinant cytokines used in this study were as follows: $50 \mathrm{pg} / 20 \mu \mathrm{L} \mathrm{IL-4}$ (R \& D systems, Minneapolis, MN) and 50 pg/20 $\mu \mathrm{L} \mathrm{IL}-6$ ( $R \& D$ systems). Skin samples from at least three mice for each genotype were harvested at 7 days after wounding.

\section{Statistical Analysis}

The Mann-Whitney U-test was used for determining the level of significance of differences between samples, and Bonferroni's test was used for multiple comparisons. A $P$ value of $<0.05$ was considered statistically significant.

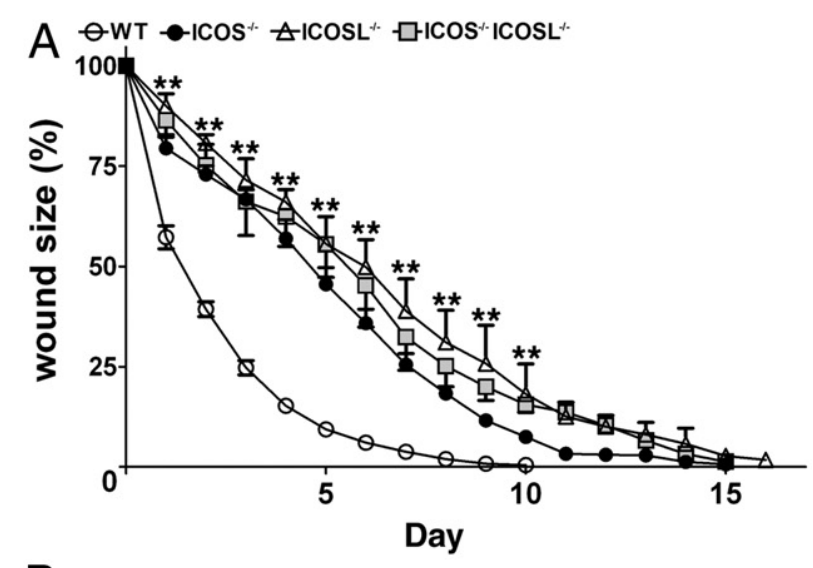

B
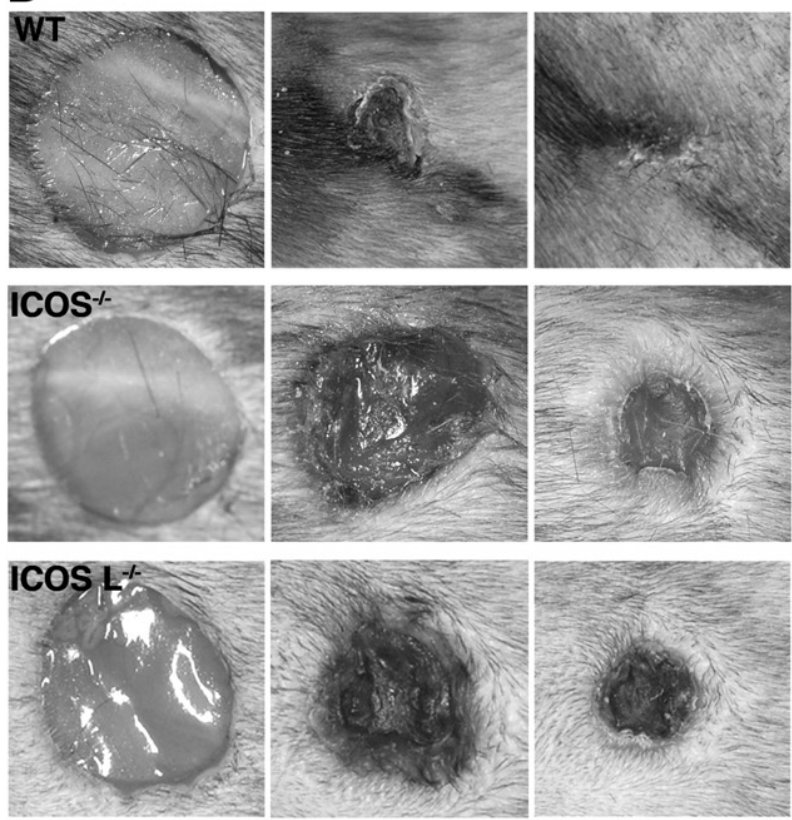

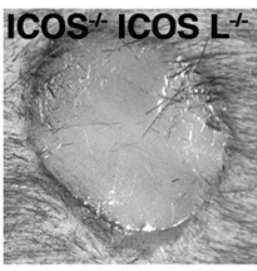

0

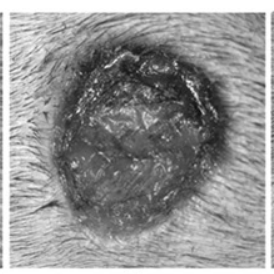

3

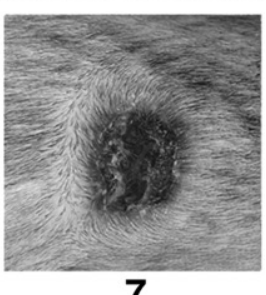

Figure 1. Cutaneous wound healing in wild-type and mutant mice. A Full-thickness cutaneous wounds were made using a 6-mm punch biopsy. The open wound area was determined by tracing the wound photos using Adobe Photoshop. Each line graph shows the mean (+SEM) results obtained from 14 mice of each group. ${ }^{* *} P<0.01$, wild-type (WT) versus mutant mice $\left(\mathrm{ICOS}^{-1-}\right.$ mice, $\mathrm{ICOSL}^{-/-}$mice, and $\mathrm{ICOS}^{-/} \mathrm{ICOSL}^{-/-}$mice). B: Representative wound closure in wild-type mice, $\operatorname{ICOS}^{-1}$ mice, $I_{C O S L^{-1}}$ mice, and $\mathrm{ICOS}^{-/-} \mathrm{ICOSL}^{-/-}$mice.

\section{Results}

\section{Open Wound Areas}

The open wound areas were measured each day after wounding to assess macroscopic healing defects (Figure 1). From day 1 to day 10, open wound areas were sig- 

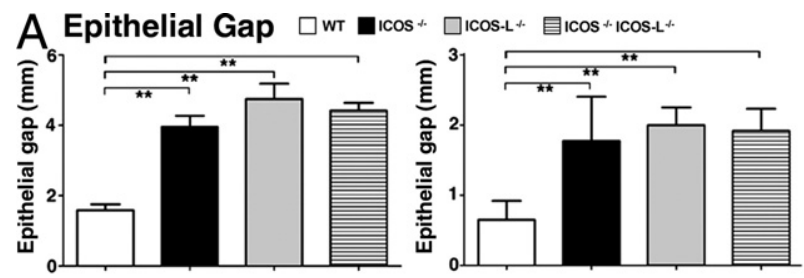

\section{B Granulation Tissue}
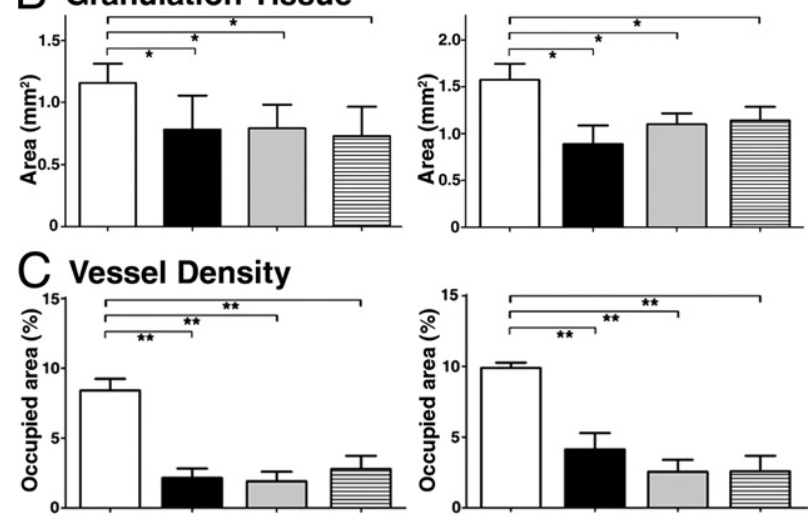

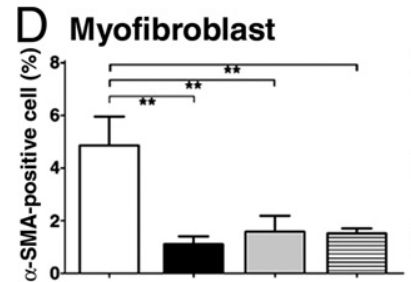

Day 3

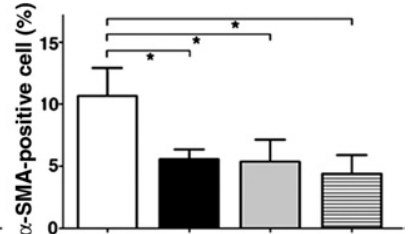

Day 7
Figure 2. Keratinocyte migration, granulation tissue formation, angiogenesis, and myofibroblast proliferation in wild-type (WT) and mutant mice. A: The distance between the migrating edges of keratinocytes under the eschar (epithelial gap) and (B) the area of granulation tissue, were both measured in tissue sections. C: Vessel density was determined as CD31-positive areas, and (D) the frequency of myofibroblasts was identified as the percentage of $\alpha$-SMA-positive cells among fibroblastic cells. Each histogram shows the mean $(+$ SEM) results obtained from at least 10 mice of each group. ${ }^{*} P<0.05,{ }^{* * *} P<0.01$.

nificantly larger in $1 \mathrm{COS}^{-/-}, \mathrm{COSL}^{-1-}$, and $1 \mathrm{COS}^{-/-}$ ICOSL $^{-1-}$ mice $(P<0.01)$ than in wild-type mice. Each mutant mouse strain showed an equivalent delay in wound healing. In wild-type mice, wounds closed completely by day 10, but wounds of mutant mice required 15 days or more. Thus, the loss of ICOS and/or ICOSL dramatically disrupted skin wound healing at an early date.

\section{Epithelial Gap}

Migration of keratinocytes under the eschar was assessed by microscopically measuring the epithelial gap (the distance between the migrating edges of keratinocytes) (Figure 2A). Keratinocyte migration was significantly inhibited in $\mathrm{ICOS}^{-1-}, \mathrm{ICOSL}^{-1-}$, and $/ \mathrm{COS}^{-1-} \mathrm{COOSL}^{-1-}$ mice relative to wild-type mice at days 3 and 7 after wounding $(P<0.01$ for both) after wounding, consistent with the defects observed in macroscopic healing (Figure 1).

\section{Granulation Tissue Formation}

Granulation tissue formation is one of the most important components in wound repair; therefore, the area of gran- ulation tissue was measured microscopically (Figure 2B). At 3 days after wounding, granulation tissue formation was reduced in $1 \mathrm{COS}^{-1-}, \mathrm{COSL}^{-1-}$, and $1 \mathrm{COS}^{-1-}$ ICOSL $^{-1-}$ mice $(P<0.05)$ relative to wild-type controls. Deficiencies in granulation tissue formation were still present at day 7 in all knockout mice as compared to wild-type controls $\left(P<0.05\right.$ for $/ \mathrm{COS}^{-/-}, I \mathrm{COSL}^{-1-}$, and ICOS $^{-1-}$ ICOSL $^{-1-}$ mice $)$.

\section{Angiogenesis}

Angiogenesis is an important event observed in the proliferative phase of wound healing. To assess the extent of angiogenesis, we performed immunohistochemical staining with anti-CD31 mAb (Figure 2C). At 3 days after wounding, the vascular density in the wound bed was significantly reduced in $/ \mathrm{COS}^{-/-}, \mathrm{COSL}^{-/-}$, and $\mathrm{COS}^{-1-} \mathrm{COSL}^{-1-}$ mice relative to wild-type controls $(P<0.01)$. At 7 days after injury, vessel density formation was also inhibited in $/ \mathrm{COS}^{-1-}, \mathrm{COSL}^{-1-}$, and $/ \mathrm{COS}^{-1-}$ ICOSL $^{-1-}$ mice $(P<0.01)$.

\section{Proliferation of Myofibroblasts}

The proliferation of myofibroblasts is also an important event in wound healing; therefore, we performed immunohistochemical staining of myofibroblasts with anti- $\alpha$ SMA mAb (Figure 2D). The percentage of cells staining positively for $\alpha$-SMA among fibroblastic cells was significantly reduced in $1 \mathrm{COS}^{-1-}, \mathrm{COSL}^{-1-}$, and $1 \mathrm{COS}^{-1-}$ ICOSL $^{-1-}$ mice $(P<0.01)$ at day 3 after wounding, as compared with wild-type controls. Similar trends were also observed at day 7 after wounding $(P<0.05$ for $\mathrm{ICOS}^{-1-}, \mathrm{ICOSL}^{-/-}$, and $/ \mathrm{COS}^{-1-} \mathrm{COOSL}^{-1-}$ mice).

\section{Infiltration of Neutrophils}

The numbers of neutrophils that migrated outside of blood vessels were assessed in wound tissue by immunohistochemical analysis using anti-myeloperoxidase mAb (Figure 3A). At 1 hour after wounding, extravasated neutrophil numbers were significantly reduced in $\mathrm{ICOS}^{-1-}, \mathrm{ICOSL}^{-1-}$, and $\mathrm{COOS}^{-1-} \mathrm{ICOSL}^{-1-}$ mice $(P<$ $0.05)$ relative to wild-type controls. Neutrophil numbers remained lower in $I \mathrm{COS}^{-1-}, \mathrm{COSL}^{-1-}$, and $1 \mathrm{COS}^{-1-}$ $\mathrm{COSL}^{-1-}$ mice at 4 hours after wounding $(P<0.05)$ relative to wild-type controls.

\section{Infiltration of CD3-Positive T Cells}

T-cell infiltration was assessed using immunohistochemical staining for CD3 (Figure 3, B and D). CD3-positive T-cell numbers were significantly reduced in $/ \mathrm{COS}^{-1-}$, $\mathrm{ICOSL}^{-1-}$, and $/ \mathrm{COS}^{-1-} / \mathrm{COSL}^{-1-}$ mice $(P<0.01)$ relative to wild-type controls on day 3. At 7 days after wounding, the numbers of CD3-positive $\mathrm{T}$ cells in $1 \mathrm{COS}^{-1-}$, $\mathrm{ICOSL}^{-1-}$, and $\mathrm{COOS}^{-1-} \mathrm{COSL}^{-1-}$ mice had increased relative to corresponding day 3 values, but remained lower than the wild-type controls ( $P<0.05$ for all groups). 
A MPO+ Neutrophil $\square$
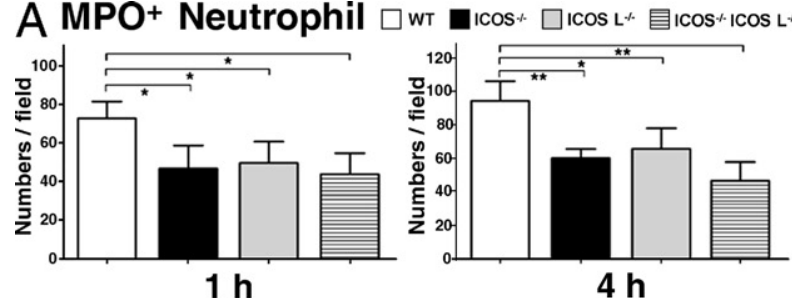

$1 \mathrm{~h}$

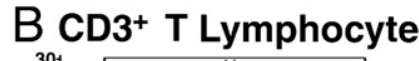

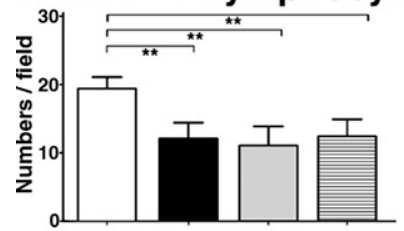

Day 3

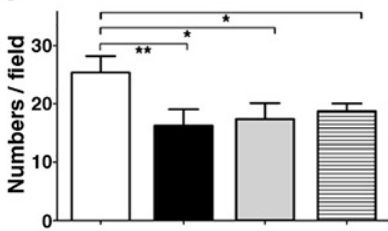

Day 7

\section{F4/80+ Macrophage}

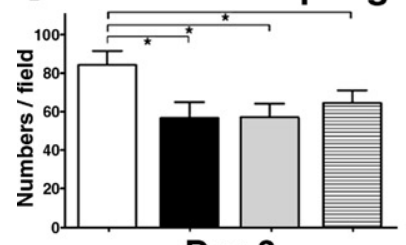

Day 3

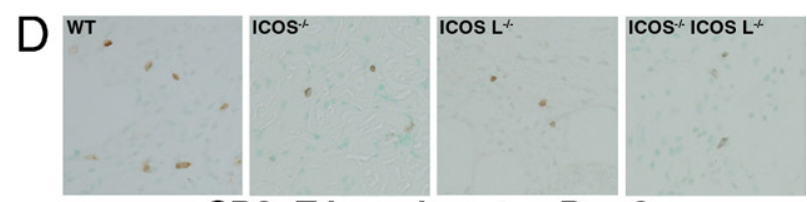

CD3+ ${ }^{+}$Lymphocyte - Day 3

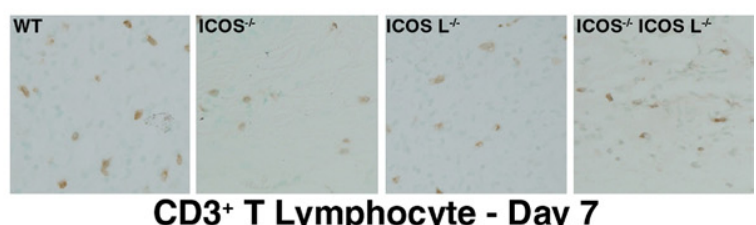

E

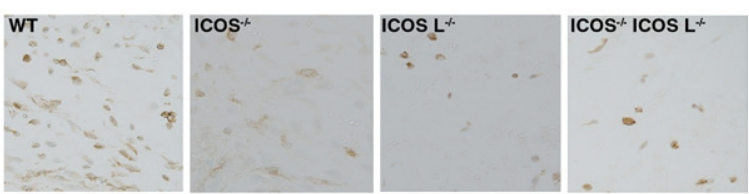

F4/80+ Macrophage - Day 3

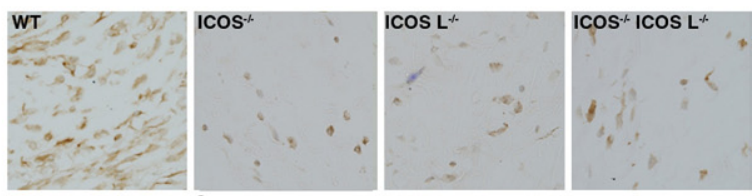

F4/80+ Macrophage - Day 7

Figure 3. Representative histological sections showing inflammatory cell infiltration into wounded skin of wild-type (WT) mice, $I C O S^{-1}$ mice $I C O S L^{-1-}$ mice, and $I \operatorname{COS}^{-1-} I C O S L^{-/-}$mice. A: Number of neutrophils was determined by counting in myeloperoxidase-stained cells per high-power field $\left(0.07 \mathrm{~mm}^{2}\right)$ at 1 and 4 hours after injury. B: Numbers of CD3-positive T cells per high-power field $\left(0.07 \mathrm{~mm}^{2}\right)$ at 3 and 7 days after wounding. C: Numbers of F 4/80-positive macrophages per high-power field $\left(0.07 \mathrm{~mm}^{2}\right)$ at 3 and 7 days after wounding. D: Sections were stained with mAbs specific for T cells $(C D 3)$. Original magnification, $\times 200$. E: Sections were stained with mAbs specific for macrophages $(\mathrm{F} 4 / 80)$. Original magnification, $\times 200$. Each histogram shows the mean $(+\mathrm{SEM})$ results obtained from at least 10 mice of each group. ${ }^{*} P<0.05,{ }^{* *} P<0.01$

\section{Infiltration of Macrophages}

Macrophage infiltration was assessed by immunohistochemistry using the F4/80 mAb (Figure 3, C and E). Macrophage numbers were significantly reduced in $I \mathrm{COS}^{-1-}, \mathrm{COSL}^{-1-}$, and $I \mathrm{COS}^{-1-} I \mathrm{COSL}^{-/-}$mice compared with wild-type mice at 3 days $(P<0.05)$ and 7 days $(P<0.05)$ after injury.

\section{T Cell-Depleted Wild-Type Mice Show Equivalent Delays in Wound Healing Compared with Mutant Mice}

To assess whether impaired T-cell function contributed to the delayed wound healing in $I \mathrm{COS}^{-/-}, I \mathrm{COSL}^{-\prime-}$, and $I \mathrm{COS}^{-1-} \mathrm{ICOSL}^{-1-}$ mice; a T cell-depleting anti-Thy 1.2 $\mathrm{mAb}$ was administered to wild-type mice 24 hours before wounding (Figure $4 \mathrm{~A}$ ). Depletion of more than $80 \%$ of $\mathrm{CD}^{+} \mathrm{T}$ cells was confirmed by flow cytometry. Wild-type mice treated with anti-Thy 1.2 mAb showed a significant delay in wound healing relative to untreated wild-type mice, with wound closure by day 10 in untreated mice and day 14 in treated mice (Figure $4 \mathrm{~A}$ ). $/ \mathrm{COS}^{-1-}$ and ICOSL ${ }^{-1-}$ mice injected with anti-Thy 1.2 mAb showed no significant changes compared with untreated $/ \mathrm{COS}^{-/-}$ and $/ \mathrm{COSL}^{-1-}$ mice. Therefore, depletion of $\mathrm{CD}^{+} \mathrm{T}$ cells from wild-type mice results in an equivalent delay in wound healing compared to both $/ \mathrm{COS}^{-1-}$ and $/ \mathrm{COSL}^{-1-}$ mice. These findings indicate that the loss of ICOS or ICOSL may be affecting wound healing via inhibition of ICOS signaling in T cells.

\section{Adoptively Transferred T Cells Improve Wound Healing}

The role of ICOS-ICOSL signaling in wound healing was assessed using adoptive transfer experiments. Splenic T cells were purified from wild-type mice or $/ \mathrm{COS}^{-/-}$mice, and $2 \times 10^{6}$ cells were transferred into $/ \mathrm{COS}^{-/-}$and $I_{C O S L^{-\prime-}}$ mice. ICOS $^{-1-}$ mice that received T cells from wild-type mice showed improved wound healing, with wound closure by day 13 (Figure 4B). There were no significant changes in the wound-healing process in ${ }^{\prime C O S}{ }^{-1-}$ recipient mice that received ICOS-negative T cells, or in $/ \mathrm{COSL}^{-/-}$mice that received wild-type T cells. Furthermore, wound sizes were significantly smaller during days 1 to 10 in $/ \mathrm{COS}^{-1-}$ recipient mice that received $\mathrm{T}$ cells from wild-type mice compared with $I \mathrm{COS}^{-1-}$ recipient mice that received T cells from $/ \mathrm{COS}^{-/-}$mice, or ICOSL ${ }^{-1-}$ recipient mice that received wild-type T cells $(P<0.05)$. These findings, together with the results of our T-cell depletion studies, indicate that ICOS-ICOSL signaling is critical for wound healing.

\section{ICOS Expression on CD4-Positive T Cells Has a Dominant Role in Wound Healing}

Next, we assessed whether ICOS expression on either $\mathrm{CD}^{+}$or $\mathrm{CD}^{+} \mathrm{T}^{+}$cells is important for wound healing. $\mathrm{CD}^{+}{ }^{+} \mathrm{T}$ cells and $\mathrm{CD} 8^{+} \mathrm{T}$ cells were purified from wild- 

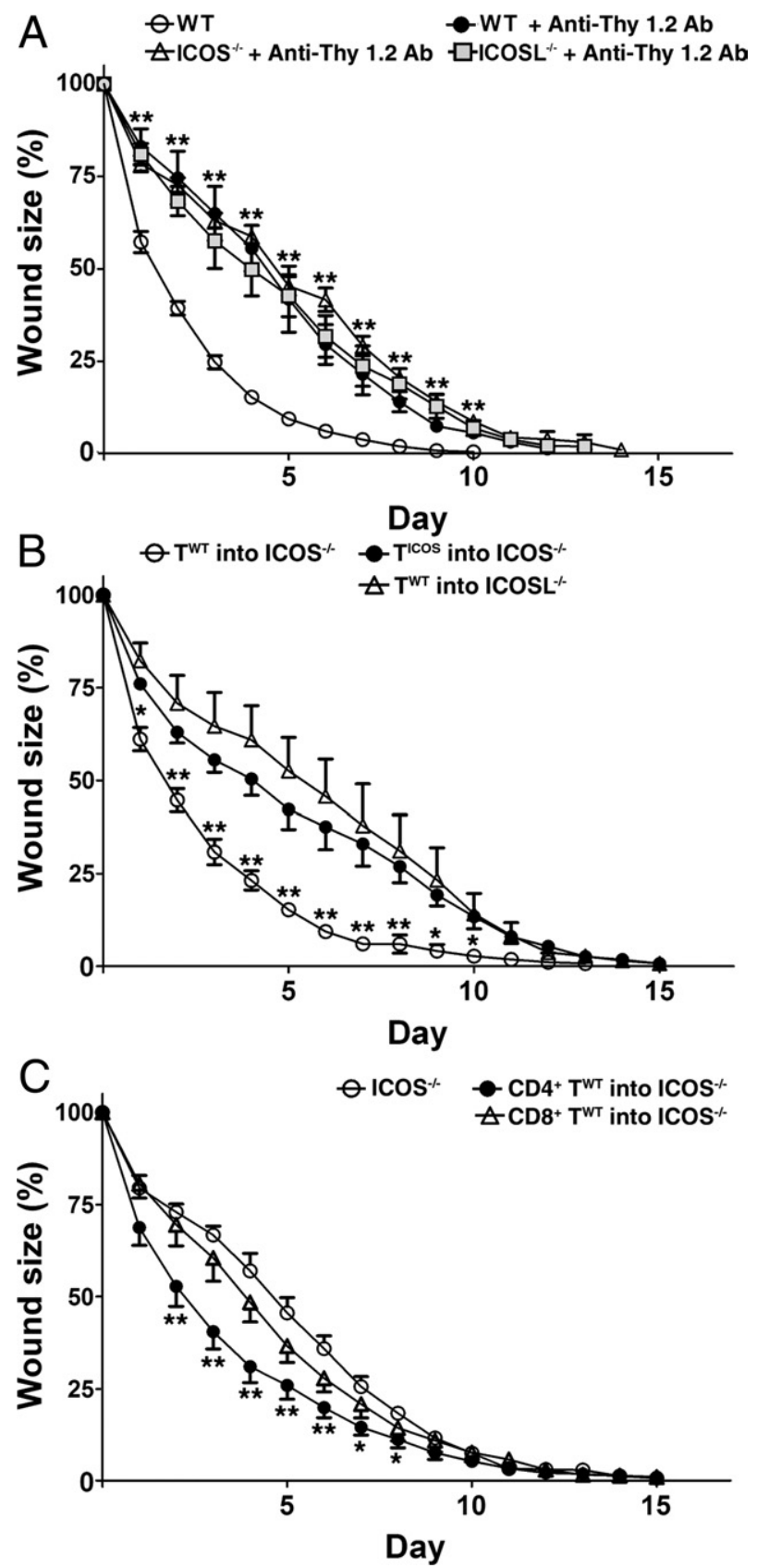

Figure 4. T cell-dependent effects on wound healing in wild-type and mutant mice. A: Wound healing in wild-type and mutant mice 24 hours after anti-Thy 1.2 mAb treatment. ${ }^{* *} P<0.01$, mAb-treated wild-type or mutant mice versus untreated wild-type mice. B: Wound healing in wild-type and mutant mice 24 hours after purified $\mathrm{T}$ cell transfer. $\mathrm{T}^{\mathrm{WT}}$ and $\mathrm{T}^{\mathrm{ICOS}}$ stand for $\mathrm{T}$ cells of wild-type and $I \mathrm{COS}^{-1}-$ mice, respectively. $\mathrm{T}^{\mathrm{WT}}$ were transferred into $I_{C O S}^{-1-}$ mice and $I C O S L^{-/-}$mice. $\mathrm{T}^{\mathrm{TCOS}}$ were transferred into other $I_{C O S}{ }^{-1}$ mice. ${ }^{*} P<0.05,{ }^{* *} P<0.01$; $\mathrm{T}^{\mathrm{WT}}$ into ICOS $^{-1}-$ mice versus both $\mathrm{T}^{\mathrm{ICOS}}$ into ICOS $^{-1-}$ mice, and $\mathrm{T}^{\mathrm{WT}}$ into ICOSL ${ }^{-/-}$mice. C: CD4-positve $\mathrm{T}^{\mathrm{WT}}$ and CD8-positve $\mathrm{T}^{\mathrm{WT}}$ were transferred into $\mathrm{ICOS}^{-1-}$ mice. ${ }^{*} \mathrm{P}<0.05$, ${ }^{* *} \mathrm{P}<$ 0.01 versus unmanipulated $I_{C O S}^{-1-}$ mice. Each line graph shows the mean $(+$ SEM) results obtained from at least five mice of each group.

type mice, and $2 \times 10^{6}$ cells of each cell type were transferred into $1 \mathrm{COS}^{-/-}$mice. Although $\mathrm{CD}^{+} \mathrm{T}$ cell transfer significantly reduced the wound size relative to unmanipulated $/ \mathrm{COS}^{-1-}$ mice during day 2 to 7 , wound closure did not occur until day 15 , similar to what was seen in unmanipulated $/ \mathrm{COS}^{-/-}$mice. $\mathrm{CD}^{+}$T-cell trans- fer did not significantly improve wound healing in $\mathrm{ICOS}^{-1-}$ mice. Thus, ICOS expression on $\mathrm{CD}^{+} \mathrm{T}$ cells rather than $\mathrm{CD}^{+} \mathrm{T}$ cells is important for wound healing.

\section{Cytokine Expression in the Wounds of Mutant Mice}

To assess the effects of ICOS and/or ICOSL loss on cytokine expression, mRNA expression levels of $\mathrm{IL}-4$, IL-6, IL-10, TNF- $\alpha$, CTGF, TGF- $\beta$, PDGF, and VEGF in the wounds were assessed by real-time RT-PCR on day 0,1 , 3 , and 7 (Figure 5A). In addition, the concentrations of IL-6, IL-10, IFN- $\gamma$, TNF- $\alpha$, and MCP- 1 in wound lysates were measured by cytometric bead array analysis, and were reported as a ratio of the total protein concentration (Figure 5B). Total protein concentrations (mean \pm SEM) in the wound lysates were comparable between strains (wild type: $12.9 \pm 6.1 \mathrm{mg} / \mathrm{mL}$; $/ \mathrm{COS}^{-/-}: 11.3 \pm 6.7 \mathrm{mg} /$ $\mathrm{mL} ; I^{C O S L}{ }^{-1-}: 12.7 \pm 6.4 \mathrm{mg} / \mathrm{mL} ; I \mathrm{COS}^{-1-} I \mathrm{COSL}^{-1-}$ : $11.3 \pm 5.5 \mathrm{mg} / \mathrm{mL}$ ). In wild-type mice, mRNA levels or protein concentrations of these cytokines and growth factors tended to increase during the process of wound healing, although mRNA levels of IL-6 and IL-10 did not increase and the protein concentration of IFN- $\gamma$ actually decreased. The mRNA levels of IL-4, IL-6, and IL-10 were significantly lower in mutant mice relative to wild-type mice from day 0 to day 7 ( $P<0.05$, Figure 5A). mRNA of TNF- $\alpha$ and CTGF tended to be reduced in mutant mice relative to wild-type mice from day 1 to day 7 . Expression levels of PDGF, TGF- $\beta$, and VEGF were not generally different between strains. The relative concentration (cytokine concentration/total proteins concentration in tissue lysates) of IL-6 (from day 0 to day 7 ) and IL-10 (from day 1 to day 3 ) in the wounds from mutant mice were lower than those of wild-type mice $(P<0.05$, Figure 5B). The relative concentrations of IFN- $\gamma, \mathrm{TNF}-\alpha$, and MCP-1 were not significantly different between strains (Figure 5B). Thus, reduced IL-4, IL-6, and IL-10 expression may be associated with the impaired wound healing in mutant mice.

\section{Effect of Cytokines on Delayed Wound Healing}

Cytokines can promote wound repair, and are produced during the initial inflammatory phase by neutrophils, macrophages, and T cells. For this reason, the effect of cytokines on the delayed wound healing observed in mutant mice was examined. As mentioned above, mutant mice demonstrated a dramatic reduction of $\mathrm{IL}-4, \mathrm{IL}-6$, and IL-10 in the wound (Figure 5). Among these cytokines, IL-4 and IL-6 have been reported as important for wound healing. ${ }^{26-28}$ Therefore, we assessed whether supplement of IL-4 or IL-6 could improve the delayed wound healing in mutant mice (Figure 6). In both $/ \mathrm{COS}^{-/-}$ mice and $/ C O S L^{-1-}$ mice supplemented with exogenous IL-6, at day 1 after injury, the gross appearance of open wound areas was significantly improved, and the wound area was reduced to a level similar to that of wild-type mice. However, this effect was not maintained, and marked differences were present by day 5 , possibly due 
A $\square$ WT $\square|\cos * \square| \cos L^{*}$ 目 $1 \cos ^{*} \cos ^{2 *}$
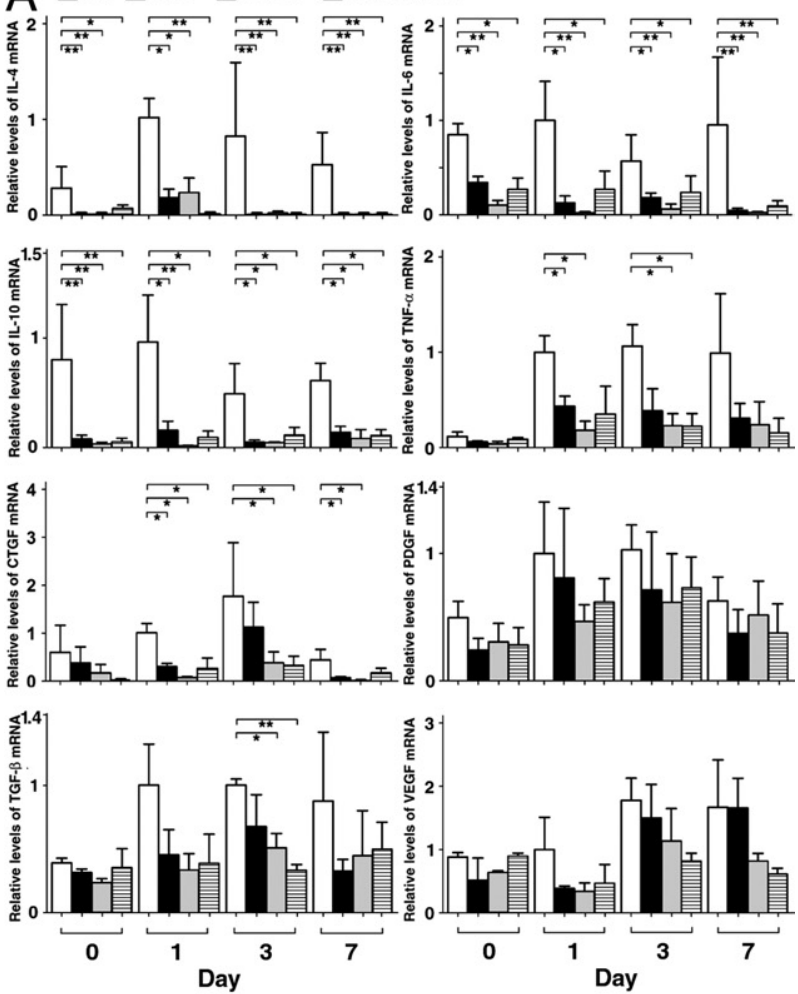

B $\square \mathrm{wt} \square \mathrm{Icos} * \square \mathrm{Icos} \mathrm{L} *$ 貝 $\mathrm{Icos} * \mathrm{Icos} \mathrm{L} *$
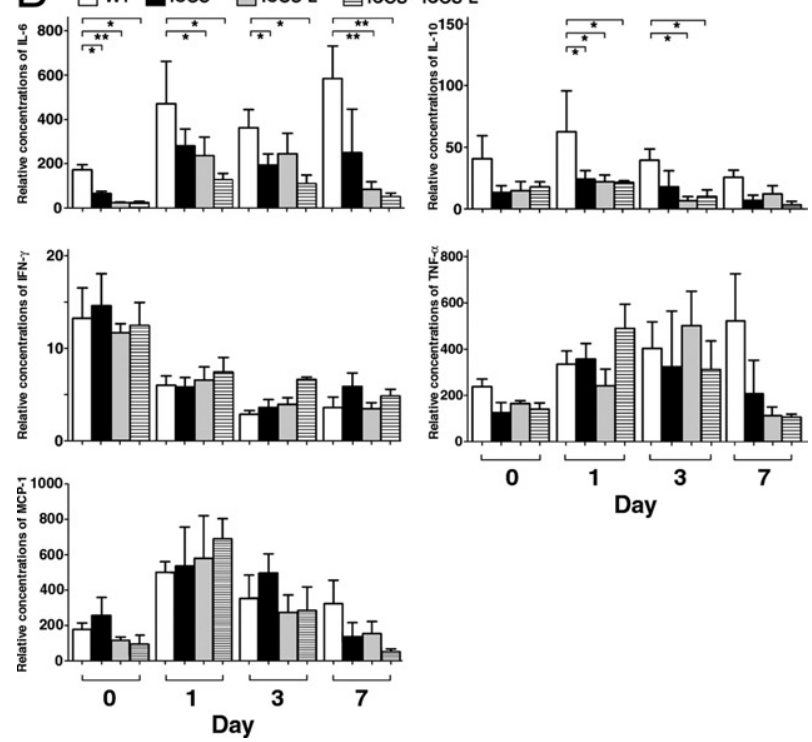

Figure 5. Cytokines, chemokines, and growth factors in wounds from wildtype (WT) and mutant mice. A: Expression of IL-4, IL-6, IL-10, TNF- $\alpha$, CTGF, PDGF, TGF- $\beta$, and VEGF mRNAs measured by quantitative RT-PCR. B: Concentrations of IL- 6 , IL-10, TNF- $\alpha$, IFN- $\gamma$, and MCP- 1 were measured by Cytometric Bead Array (BD Biosciences) analysis in supernatants of wound homogenates. Total protein in the supernatant was measured by bicinchoninic acid protein assay. Relative concentrations of each cytokine [cytokine concentration (in picograms per milliliter) divided by total protein concentration (in milligrams per milliliter)] in tissue lysates were shown. Each histogram shows the mean (+SEM) results obtained from at least six mice of each group. ${ }^{*} P<0.05,{ }^{* * *} P<0.01$.

to blocking of cytokine infiltration by the wound-fixed eschar. On the other hand, application of IL-4 did not show any positive effect on early wound healing in mutant mice. Thus, a loss of ICOS-ICOSL signaling may delay the early phase of wound healing by reducing IL-6 expression in the wounded skin.

\section{Discussion}

To our knowledge, this is the first report that has shown significant roles for T-cell costimulatory molecules in wound healing. Disruption of the ICOS-ICOSL pathway dramatically delayed skin wound healing in mice. The loss of ICOS and/or ICOSL resulted in markedly reduced numbers of infiltrating $T$ cells, macrophages, and neutrophils into wounds. The delayed wound healing observed in mutant mice was similar to that seen in wild-type mice that were depleted of T cells by anti-Thy $1.2 \mathrm{mAb}$. T-cell transfer, specifically transfer of $\mathrm{CD} 4^{+} \mathrm{T}$ cells rather than $\mathrm{CD}^{+} \mathrm{T}$ cells, improved wound healing in $/ \mathrm{COS}^{-/-}$mice. Furthermore, all three types of knockout mice showed dramatic reductions in cytokines, especially Th2 cytokines such as IL-4, IL-6, and IL-10, in the skin during wound healing. Application of IL-6, but not IL-4, significantly improved the early wound healing in mutant mice. Together, these findings indicate that ICOS-ICOSL signaling and subsequent production of cytokines, such as IL-6, are critical for wound healing.

In this study, we observed a surprising delay in wound healing in mice deficient for ICOS, ICOSL, or both ICOS and ICOSL. Transfer of wild-type $T$ cells reversed the delay in wound healing observed in $1 \mathrm{COS}^{-/-}$mice, resulting in responses that were almost equivalent to those of wild-type mice. This finding confirmed the critical roles played by T cell-expressed ICOS during wound healing. Furthermore, ICOS-ICOSL signaling is required for the function of ICOS in this process, since transfer of wildtype $\mathrm{T}$ cells did not improve wound healing in $/ \mathrm{COSL}^{-/-}$
A

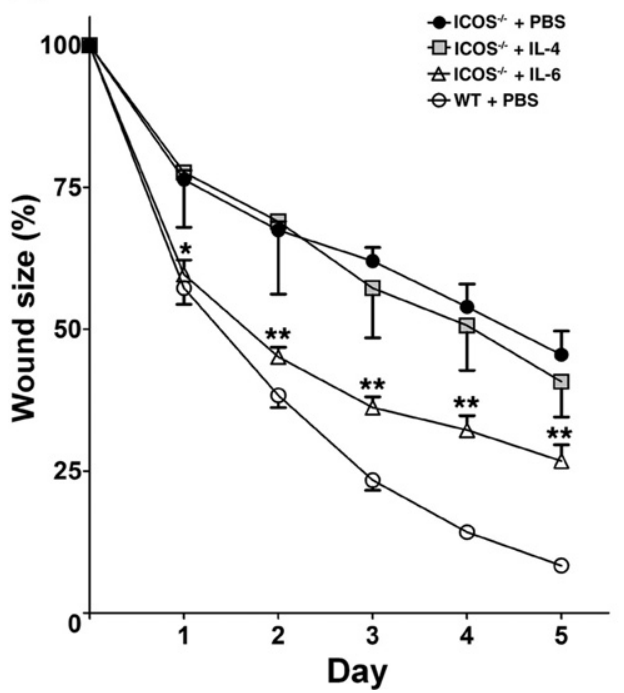

$\mathrm{B}$

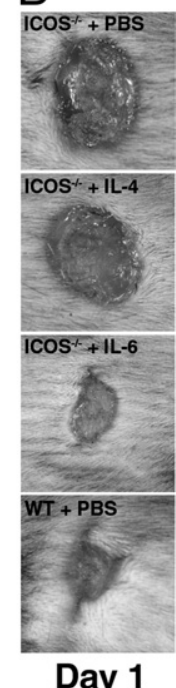

Figure 6. A: Effect of cytokines (IL-4 and IL-6) on delayed wound repair in mice deficient for ICOS or ICOSL. Cytokines were applied to each wound in $20 \mu \mathrm{L}$ of PBS immediately after wounding and every 24 hours after wounding. Each line graph shows the mean $(+\mathrm{SEM})$ results obtained from at least three mice of each group. ${ }^{*} P<0.05,{ }^{* * *} P<0.01 ;$ ICOS $^{-1-}$ mice + PBS versus $\mathrm{ICOS}^{-1-}$ mice + IL-6. B: Representative wound closure in each group. WT wild type. 
mice. T-cell depletion in wild-type mice using anti-Thy 1.2 $\mathrm{Ab}$ led to delayed wound healing that was comparable to that observed in $/ \mathrm{COS}^{-/-}$and/or $/ \mathrm{COSL}^{-/-}$mice. Previous studies demonstrated that global T-cell depletion using anti-Thy 1.2 antibody inhibited wound healing in wild-type mice ${ }^{29,30}$ is consistent with our findings. There is a controversy regarding the roles of $\mathrm{CD} 4^{+} \mathrm{T}$ cells in wound healing. One group reported that $\mathrm{CD} 4^{+} \mathrm{T}$-cell depletion did not significantly affect the wound healing in mice, ${ }^{31}$ whereas another group showed a significantly impaired wound healing by $\mathrm{CD} 4^{+} \mathrm{T}$-cell depletion in rats. ${ }^{32}$ On the other hand, the depletion of $\mathrm{CD} 8^{+} \mathrm{T}$ cells improved wound healing in both groups' studies. ${ }^{31,32}$ Although we did not perform depletion studies of $\mathrm{CD} 4^{+} \mathrm{T}$ cells or $\mathrm{CD} 8^{+} \mathrm{T}$ cells, our adoptively transferred experiment of $\mathrm{CD} 4^{+} \mathrm{T}$ cells or $\mathrm{CD} 8^{+} \mathrm{T}$ cells indicated that ICOS expressed on $\mathrm{CD}^{+}{ }^{+} \mathrm{T}$ cells rather than $\mathrm{CD} 8^{+} \mathrm{T}$ cells are important for wound healing. This finding is not surprising, since ICOS is predominantly expressed on $\mathrm{CD}^{+} \mathrm{T}$ cells relative to $C D 8^{+} T$ cells, especially before activation. ${ }^{9}$ These results suggest that ICOS has a central role in the positive function of $T$ cells during wound healing.

A recent study demonstrated that augmenting ICOS costimulation enhances the migration of lymphocytes, including $B$ cells and non-antigen-specific $T$ cells, by increasing the expression of chemokines in the lymph nodes. ${ }^{33}$ Another study showed that transfer of ICOSenriched $T$ cells followed by allergen airway challenge induced infiltration of recipient lymphocytes. ${ }^{34}$ Therefore, ICOS-ICOSL signaling is likely important for lymphocyte migration, although direct effects of ICOS on lymphocyte chemotaxis have not yet been examined. Consistent with this idea, mutant mice exhibited a marked reduction in inflammatory cell infiltration including neutrophils, lymphocytes, and macrophages during wound healing. The inflammatory response is believed to be instrumental in supplying cytokines, chemokines, and growth factors that orchestrate the cell movement necessary for wound repair. ${ }^{1-4}$ An absence or a decrease in macrophage number at wound sites impairs tissue repair, ${ }^{35}$ and transfer of macrophages into aged mice accelerates wound healing. ${ }^{36}$ In addition to our current findings, it has been reported previously that $\mathrm{T}$-cell depletion using antiThy 1.2 Ab significantly inhibits wound healing in mice. ${ }^{37}$ Thus, inflammatory cell recruitment is considered to be important for wound healing, and one possible explanation for the delayed wound repair in $I \mathrm{COS}^{-1-}$ and ICOSL $^{-1-}$ mice could be impaired inflammatory cell infiltration. Unfortunately, Abs against ICOS or ICOSL that can clearly stain positive cells in the skin were not available.

All components necessary for wound healing, such as keratinocyte migration (epithelial gap), granulation tissue formation, angiogenesis, and myofibroblast proliferation were suppressed in $I \mathrm{COS}^{-/-}, \mathrm{ICOSL}^{-/-}$, and doubleknockout mice. These defects may be due to the reduction of various cytokines produced directly or indirectly by infiltrating inflammatory cells in the wound. Interestingly, Th2 cytokines such as IL-4, IL-6, and IL-10 were markedly suppressed in the skin of mutant mice before and after wounding. It is well known that ICOS-ICOSL signaling has a pivotal role in cytokine production by $T$ cells, and this is particularly true for the induction of Th2 cytokines rather than Th1 cytokines.,10-12 Our findings support a role for ICOS in Th2 cytokine production during skin wound healing.

Importantly, application of IL-6, but not IL-4, significantly improved wound closure to the levels of wild-type mice during early wound healing. Prior studies had shown that IL-6-deficient mice have a marked delay in skin wound healing, 27,28 and that IL-6 deficiency reduced inflammatory cell infiltration, collagen deposition, and angiogenesis at wound sites. ${ }^{28}$ Furthermore, it has been demonstrated that IL-6 induces keratinocyte migration via signal transducer and activator of transcription 3 (STAT3) activation. ${ }^{38}$ In fact, STAT3 is essential for keratinocyte migration, and STAT3-disrupted mice exhibit significantly delayed wound healing. ${ }^{39}$ Therefore, the markedly suppressed IL-6 in our study may explain, at least in part, the delayed wound healing in $1 \mathrm{COS}^{-1-}$ and ICOSL ${ }^{-/-}$mice. A previous report demonstrated that topical administration of IL-4 significantly accelerated wound healing, whereas IL-4 antisense oligonucleotides significantly inhibited healing. ${ }^{26}$ By contrast, IL-10 is an inhibitory factor for the remodeling of extracellular matrix during wound healing. ${ }^{40}$ Addition of a neutralizing anti-IL-10 $\mathrm{Ab}$ inhibits the infiltration of neutrophils and macrophages toward the wound.$^{41}$ Therefore, reduced IL-10 expression is not likely contributing to the delayed wound healing seen in mutant mice in the current study, although reduced cell infiltration may be partially induced by decreased IL-10 expression. Although IFN- $\gamma$ has been known to enhance wound healing, ${ }^{42}$ the concentration of IFN- $\gamma$ in mutant mice was not significantly different from that seen in wild-type mice. Therefore, our findings suggest that loss of ICOS-ICOSL signaling reduces expression of cytokines such as IL-6, and thereby delays wound healing. Interestingly, Th2 cytokines, including IL-4, IL-6, and IL-10, were remarkably reduced even in the unwounded homeostatic skin (day 0) of knockout mice compared with wild-type mice. This may explain the dramatic early delay in wound healing similar to that of IL6 -deficient mice. ${ }^{27,28}$

It is currently thought that ICOS and ICOSL are a single receptor-ligand pair with no other known binding partners. ${ }^{17}$ Previous studies have shown that $/ \mathrm{COS}^{-1-}$ mice and $I C O S L^{-1-}$ mice have similar phenotypes. ${ }^{16,17}$ Consistent with this idea, in the wound-healing model used in our current study, $I \mathrm{COS}^{-/-}$mice and/or $I \mathrm{COSL}^{-/-}$mice exhibited similar delays in wound healing. Most studies have investigated the roles of ICOS or ICOSL in disease models related to antigen-specific adaptive immunity. ${ }^{18-21}$ Therefore, it is unexpected that T-cell costimulatory signals, including ICOS-ICOSL, have roles in wound healing. Although ICOS is expressed on effector and memory $T$ cells, ICOSL is constitutively expressed on macrophages and dendritic cells that contribute to innate immunity, in addition to expression on B cells. ${ }^{5-7}$ Several studies have reported that ICOSL is expressed on subsets of epidermal cells, mesenchymal cells, and endothelial cells, ${ }^{7,43,44}$ although we could not detect expression on these cell types, at least by immunohistochemical 
staining (data not shown). Several recent studies, including our bleomycin model, showed the roles of ICOS and ICOSL in innate immune responses, including inflammation. ${ }^{22,23}$ Our findings also suggest that ICOS-ICOSL signaling contributes to innate immunity during wound healing. Alternatively, ICOS-ICOSL signaling may affect cytokine balance or the production of cytokines in organs such as the skin under homeostatic and pathological conditions. Further investigation will be needed to clarify the multiple, robust, and complicated functions of ICOSICOSL signaling for clinical application of wound healing.

\section{References}

1. Singer AJ, Clark RAF: Cutaneous wound healing. N Engl J Med 1999, 341:738-746

2. Martin P: Wound healing-aiming for perfect skin regeneration. Science 1997, 276:75-81

3. Kondo T, Ishida Y: Molecular pathology of wound healing. Forensic Sci Int 2010, 203:93-98

4. Brancato SK, Albina JE: Wound macrophages as key regulators of repair: origin, phenotype, and function. Am J Pathol 2011, 178:19-25

5. Hutloff A, Dittrich AM, Beier KC, Eljaschewitsch B, Kraft R, Anagnostopoulos I, Kroczek RA: ICOS is an inducible T-cell co-stimulator structurally and functionally related to CD28. Nature 1999, 397:263-266

6. Yoshinaga SK, Whoriskey JS, Khare SD, Sarmiento U, Guo J, Horan T, Shih G, Zhang M, Coccia MA, Kohno T, Tafuri-Bladt A, Brankow D, Campbell P, Chang D, Chiu L, Dai T, Duncan G, Elliott GS, Hui A, McCabe SM, Scully S, Shahinian A, Shaklee CL, Van G, Mak TW, Senaldi G: T-cell co-stimulation through B7RP-1 and ICOS. Nature 1999, 402:827-832

7. Greenwald RJ, Freeman GJ, Sharpe AH: The B7 family revisited. Annu Rev Immunol 2005, 23:515-548

8. Swallow MM, Wallin JJ, Sha WC: B7h, a novel costimulatory homolog of B7.1 and B7.2, is induced by TNFalpha. Immunity 1999, 11:423-432

9. McAdam AJ, Chang TT, Lumelsky AE, Greenfield EA, Boussiotis VA, Duke-Cohan JS, Chernova T, Malenkovich N, Jabs C, Kuchroo VK, Ling V, Collins M, Sharpe AH, Freeman GJ: Mouse inducible costimulatory molecule (ICOS) expression is enhanced by CD28 costimulation and regulates differentiation of CD4+ T cells. J Immunol 2000, 165:5035-5040

10. Nurieva RI, Chung $Y$, Hwang D, Yang $X O$, Kang HS, Ma L, Wang YH, Watowich SS, Jetten AM, Tian Q, Dong C: Generation of T follicular helper cells is mediated by interleukin-21 but independent of $\mathrm{T}$ helper 1, 2, or 17 cell lineages. Immunity 2008, 29:138-149

11. Coyle AJ, Gutierrez-Ramos JC: The role of ICOS and other costimulatory molecules in allergy and asthma. Springer Semin Immunopathol 2004, 25:349-359

12. Lohning M, Hutloff A, Kallinich T, Mages HW, Bonhagen K, Radbruch A, Hamelmann E, Kroczek RA: Expression of ICOS in vivo defines CD4+ effector T cells with high inflammatory potential and a strong bias for secretion of interleukin 10. J Exp Med 2003, 197:181-193

13. Bauquet AT, Jin H, Paterson AM, Mitsdoerffer M, Ho IC, Sharpe AH, Kuchroo VK: The costimulatory molecule ICOS regulates the expression of C-Maf and IL-21 in the development of follicular T helper cells and TH-17 cells. Nat Immunol 2009, 10:167-175

14. Burmeister $Y$, Lischke T, Dahler AC, Mages HW, Lam KP, Coyle AJ, Kroczek RA, Hutloff A: ICOS controls the pool size of effector-memory and regulatory T cells. J Immunol 2008, 180:774-782

15. Akbari O, Freeman GJ, Meyer EH, Greenfield EA, Chang TT, Sharpe AH, Berry G, DeKruyff RH, Umetsu DT: Antigen-specific regulatory T cells develop via the ICOS-ICOS-ligand pathway and inhibit allergeninduced airway hyperreactivity. Nat Med 2002, 8:1024-1032

16. Mak TW, Shahinian A, Yoshinaga SK, Wakeham A, Boucher LM, Pintilie M, Duncan G, Gajewska BU, Gronski M, Eriksson U, Odermatt B, Ho A, Bouchard D, Whorisky JS, Jordana M, Ohashi PS, Pawson T, Bladt $F$, Tafuri A: Costimulation through the inducible costimulator ligand is essential for both $\mathrm{T}$ helper and $\mathrm{B}$ cell functions in $\mathrm{T}$ celldependent B cell responses. Nat Immunol 2003, 4:765-772
17. Nurieva RI, Mai XM, Forbush K, Bevan MJ, Dong C: B7h is required for $T$ cell activation, differentiation, and effector function, Proc Natl Acad Sci U S A 2003, 100:14163-14168

18. Dong C, Juedes AE, Temann UA, Shresta S, Allison JP, Ruddle NH, Flavell RA: ICOS co-stimulatory receptor is essential for T-cell activation and function. Nature 2001, 409:97-101

19. Rottman JB, Smith T, Tonra JR, Ganley K, Bloom T, Silva R, Pierce B, Gutierrez-Ramos JC, Ozkaynak E, Coyle AJ: The costimulatory molecule ICOS plays an important role in the immunopathogenesis of EAE. Nat Immunol 2001, 2:605-611

20. Kopf M, Coyle AJ, Schmitz N, Barner M, Oxenius A, Gallimore A, Gutierrez-Ramos JC, Bachmann MF: Inducible costimulator protein (ICOS) controls $\mathrm{T}$ helper cell subset polarization after virus and parasite infection. J Exp Med 2000, 192:53-61

21. Ozkaynak E, Gao W, Shemmeri N, Wang C, Gutierrez-Ramos JC, Amaral J, Qin S, Rottman JB, Coyle AJ, Hancock WW: Importance of ICOS-B7RP-1 costimulation in acute and chronic allograft rejection. Nat Immunol 2001, 2:591-596

22. Tanaka C, Fujimoto M, Hamaguchi Y, Sato S, Takehara K, Hasegawa $\mathrm{M}$ : Inducible costimulator ligand regulates bleomycin-induced lung and skin fibrosis in a mouse model independently of the inducible costimulator/inducible costimulator ligand pathway. Arthritis Rheum 2010, 62:1723-1732

23. Dianzani C, Minelli R, Mesturini R, Chiocchetti A, Barrera G, Boscolo S, Sarasso C, Gigliotti CL, Sblattero D, Yagi J, Rojo JM, Fantozzi R, Dianzani U: B7h triggering inhibits umbilical vascular endothelial cell adhesiveness to tumor cell lines and polymorphonuclear cells. J Immunol 2010, 185:3970-3979

24. Mori R, Kondo T, Nishie T, Ohshima T, Asano M: Impairment of skin wound healing in beta-1,4-galactosyltransferase-deficient mice with reduced leukocyte recruitment. Am J Pathol 2004, 164:1303-1314

25. Tomita $Y$, Nomoto K: Prevention of induction of unresponsiveness to class I antigens by veto activity of donor marrow in cylophosphamidetreated mice. Transplantation 1993, 56:1473-1480

26. Salmon-Ehr V, Ramont L, Godeau G, Birembaut $P$, Guenounou M, Bernard P, Maquart FX: Implication of interleukin-4 in wound healing. Lab Invest 2000, 80:1337-1343

27. Gallucci RM, Simeonova PP, Matheson JM, Kommineni C, Guriel JL, Sugawara T, Luster MI: Impaired cutaneous wound healing in interleukin-6-deficient and immunosuppressed mice. FASEB J 2000, 14: 2525-2531

28. Lin ZQ, Kondo T, Ishida Y, Takayasu T, Mukaida N: Essential involvement of IL-6 in the skin wound-healing process as evidenced by delayed wound healing in IL-6-deficient mice. J Leukoc Biol 2003, 73:713-721

29. Barbul A, Shawe T, Rotter SM, Efron JE, Wasserkrug HL, Badawy SB: Wound healing in nude mice: a study on the regulatory role of lymphocytes in fibroplasia. Surgery 1989, 105:764-769

30. Efron JE, Frankel HL, Lazarou SA, Wasserkrug HL, Barbul A: Wound healing and T-lymphocytes. J Surg Res 1990, 48:460-463

31. Barbul A, Breslin RJ, Woodyard JP, Wasserkrug HL, Efron G: The effect of in vivo $T$ helper and $T$ suppressor lymphocyte depletion on wound healing. Ann Surg 1989, 209:479-483

32. Davis PA, Corless DJ, Aspinall R, Wastell C: Effect of CD4(+) and CD8(+) cell depletion on wound healing. Br J Surg 2001, 88:298-304

33. Tesciuba AG, Shilling RA, Agarwal MD, Bandukwala HS, Clay BS, Moore TV, Weinstock JV, Welcher AA, Sperling AI: ICOS costimulation expands Th2 immunity by augmenting migration of lymphocytes to draining lymph nodes. J Immunol 2008, 181:1019-1024

34. Beier KC, Hutloff A, Lohning M, Kallinich T, Kroczek RA, Hamelmann $\mathrm{E}$ : Inducible costimulator-positive $T$ cells are required for allergeninduced local B-cell infiltration and antigen-specific IgE production in lung tissue. J Allergy Clin Immunol 2004, 114:775-782

35. Leibovich SJ, Ross R: The role of the macrophage in wound repair: a study with hydrocortisone and antimacrophage serum. Am J Pathol 1975, 78:71-100

36. Danon D, Kowatch MA, Roth GS: Promotion of wound repair in old mice by local injection of macrophages, Proc Natl Acad Sci U S A 1989, 86:2018-2020

37. Peterson JM, Barbul A, Breslin RJ, Wasserkrug HL, Efron G: Significance of T-lymphocytes in wound healing. Surgery 1987, 102:300-305

38. Gallucci RM, Sloan DK, Heck JM, Murray AR, O'Dell SJ: Interleukin 6 indirectly induces keratinocyte migration. J Invest Dermatol 2004, 122:764-772 
39. Sano S, Itami S, Takeda K, Tarutani M, Yamaguchi $Y$, Miura $H$, Yoshikawa K, Akira S, Takeda J: Keratinocyte-specific ablation of Stat3 exhibits impaired skin remodeling, but does not affect skin morphogenesis. EMBO J 1999, 18:4657-4668

40. Moroguchi A, Ishimura K, Okano K, Wakabayashi H, Maeba T, Maeta $\mathrm{H}$ : Interleukin-10 suppresses proliferation and remodeling of extracellular matrix of cultured human skin fibroblasts. Eur Surg Res 2004 36:39-44

41. Sato $Y$, Ohshima $T$, Kondo $T$ : Regulatory role of endogenous interleukin-10 in cutaneous inflammatory response of murine wound healing. Biochem Biophys Res Commun 1999, 265:194-199
42. Ishida $Y$, Kondo T, Takayasu T, Iwakura $Y$, Mukaida N: The essential involvement of cross-talk between IFN-gamma and TGF-beta in the skin wound-healing process. J Immunol 2004, 172:18481855

43. Khayyamian S, Hutloff A, Buchner K, Grafe M, Henn V, Kroczek RA, Mages HW: ICOS-ligand, expressed on human endothelial cells, costimulates Th1 and Th2 cytokine secretion by memory CD4+ T cells, Proc Natl Acad Sci U S A 2002, 99:6198-6203

44. Kajiwara K, Morishima H, Akiyama K, Yanagihara Y: Expression and function of the inducible costimulator ligand $\mathrm{B} 7-\mathrm{H} 2$ in human airway smooth muscle cells. Allergol Int 2009, 58:573-583 